\title{
Investigation of equine influenza transmission in NSW: walk, wind or wing?
}

\author{
Paula J. Spokes ${ }^{\mathrm{A}, \mathrm{C}}$, Andrew J. N. Marich ${ }^{\mathrm{B}}$, \\ Jennie A. Musto ${ }^{\mathrm{B}}$, Kate A. Ward $^{\mathrm{A}}$, \\ Adam T. Craig ${ }^{\mathrm{A}}$ and Jeremy M. Mc Anulty ${ }^{\mathrm{B}}$ \\ ${ }^{\mathrm{A}} \mathrm{NSW}$ Public Health Officer Training Program, \\ NSW Department of Health \\ ${ }^{\mathrm{B} C o m m u n i c a b l e ~ D i s e a s e s ~ B r a n c h, ~ N S W ~ D e p a r t m e n t ~ o f ~ H e a l t h ~}$ \\ ${ }^{\mathrm{C}}$ Corresponding author. Email: \\ paula.spokes@doh.health.nsw.gov.au
}

\begin{abstract}
Objectives: An outbreak of equine influenza occurred in New South Wales in 2007. In addition to the local spread of the disease between bordering properties, windborne spread over several kilometres had been postulated as a possible method of transmission in this outbreak. This study aimed to describe potential modes of transmission for a property infected with equine influenza where no apparent epidemiological links to other infected properties were reported. Methods: A semi-structured questionnaire was administered to owners of affected properties. The questionnaire collected detailed transmission-risk information, including personnel movements, equipment sharing, and horse and other animal movements. Results: Interviews with property owners from one geographic area suggested the potential for birds and other animals - rather than wind - to facilitate transmission of equine influenza. Conclusion: This study described the potential for mechanical spread of equine influenza. Further research, including laboratory testing of bird plumage following contact with infected horses, may be useful to confirm the possibility of avian fomite transmission.
\end{abstract}

In August 2007, the New South Wales (NSW) Department of Primary Industries (DPI) identified an outbreak of equine influenza (EI) in the Sydney area. More than 5000 properties in NSW were eventually affected by the equine influenza $\mathrm{A}, \mathrm{H} 3 \mathrm{~N} 8$ virus.
While the mode of transmission of EI is incompletely understood, the virus is thought to be transmitted via droplets from infected, coughing horses. ${ }^{1}$ The virus can survive on skin, fabrics and surfaces of contaminated equipment, but survival in the air may be reduced in conditions of high relative humidity (Table 1). ${ }^{1}$ Animals other than horses are not thought to be epidemiologically significant for the spread of EI.

Infected, coughing horses have been reported to spread the EI virus $35 \mathrm{~m}$ and possibly further under favourable air and wind-drift conditions. ${ }^{1}$ In an outbreak of EI in 1965, horses segregated $27.4 \mathrm{~m}$ away from known infected horses reportedly became infected; however, virus transfer by people or equipment could not be excluded. ${ }^{2}$ Virus spread by humans and fomites may have played a significant role in the spread of EI in the 2007 outbreak in NSW (Table 1). ${ }^{3}$ An enquiry into the outbreak found that the virus most likely left the Eastern Creek Quarantine Station on the contaminated clothing or equipment of a person who had been in contact with an infected horse. ${ }^{4}$

In addition to the local spread of EI between bordering properties, windborne spread of EI over several kilometres dependent on atmospheric and climatic conditions - had been postulated as a possible method of transmission in the 2007 outbreak in NSW. ${ }^{5}$ Anecdotal reports of windborne spread over distances of up to $8 \mathrm{~km}$ have been suggested during outbreaks in South Africa in 1986 and Jamaica in 1989, although other modes of transmission such as contaminated personnel and equipment could not be excluded. 6,7 Direct contact with infected horses and contaminated equipment and associated personnel were identified as the most important factors in the rapid spread of EI in the South African outbreak in $1986 .{ }^{8}$

Windborne spread of infection has not been reported for human influenza viruses and, as such, the 2007 EI outbreak presented a unique opportunity to understand the potential for the windborne spread of influenza that may be relevant to both horses and humans.

The NSW Exotic Diseases of Animals Act 1991 requires anyone with contact with infected horses or horse products (including objects or vehicles) to comply with disinfection guidelines. ${ }^{9}$ Penalties, including fines or imprisonment, apply to people who do not comply. Information was 
Table 1. Conditions required for the viability of equine influenza virus on some surfaces

\begin{tabular}{|c|c|c|}
\hline Surface & Conditions required & Length of virus viability \\
\hline Fabric/clothing & $\begin{array}{l}\text { Humidity of } 35-40 \% \\
\text { Temperature of } 28^{\circ} \mathrm{C}\end{array}$ & $8-12$ hours \\
\hline Stainless steel or plastic & $\begin{array}{l}\text { Humidity } 35-40 \% \\
\text { Temperature of } 28^{\circ} \mathrm{C}\end{array}$ & 24-48 hours \\
\hline Tap water (pH 7.0) & Temperature up to $37^{\circ} \mathrm{C}$ & 2 days \\
\hline Soil & $\begin{array}{l}\text { In dark storage } \\
\text { Temperature of } 18^{\circ} \mathrm{C}\end{array}$ & 24 hours \\
\hline Soil & $\begin{array}{l}\text { In direct sunlight } \\
\text { Temperature of } 15^{\circ} \mathrm{C}\end{array}$ & 8 hours \\
\hline
\end{tabular}

provided to property owners regarding disinfection practices and on-farm biosecurity measures. Property owners who suspected that their horses had been infected with EI were required, under the Act, to contact their local veterinarian or the DPI disease hotline. ${ }^{10}$

During the outbreak some infected properties were geographically isolated from known infected properties and restricted areas, and had no apparent epidemiological links to a source of infection. These properties presented an opportunity to explore factors that may have been associated with transmission, including the likelihood of windborne spread.

In this study we aimed to describe potential modes of transmission for a property infected with EI where there were no apparent epidemiological links to other infected properties.

\section{Methods}

The study area was located on the south-western outskirts of Sydney in NSW. The area was chosen because it contained several infected properties geographically separate from infected properties with known epidemiological links. The area was also located near the Local Disease Control Centre (LDCC) where the investigation team was based.

Epidemiologists from the LDCC and NSW Health reviewed the case-file information to collect onset dates and identify infected properties from the study area. Properties with no known epidemiological links to an infected property were determined through case-note review and discussion with field veterinarians involved in the initial investigation. Outbreak maps developed by DPI using the FrontGate Geographical Information System program were used to locate infected and neighbouring properties. ${ }^{11}$ Daily weather observations from an airport, approximately $6 \mathrm{~km}$ north-east of the study group, were used as a proxy measure for the area of interest.

A semi-structured questionnaire was developed to collect detailed transmission-risk information including personnel movements, equipment sharing, and horse and other animal movements. The questionnaire was administered to owners of infected properties to identify potential epidemiological links. The questionnaire was administered via a telephone interview or in person at property boundaries because of biosecurity measures and the risk of infection for non-infected properties. One property (property E) was studied in detail because of its apparent geographical separation from other infected properties. Owners of properties with no horses (as reported by neighbours) were not interviewed. Interviews were conducted in October 2007.

\section{Results}

Four properties within a $1 \mathrm{~km}$ radius in this area (properties A, B, C and D) reported EI infection to the DPI. The first case (property A) reported the onset of symptoms as 4 September 2007. This property was subsequently found to have epidemiological links to Centennial Park, a significant spread site prior to the statewide lockdown of the movement of horses. Other properties within the study area which shared common boundaries with property A subsequently reported infection (Table 2). Property E reported to the LDCC onset of EI symptoms on 10 September. This property was approximately $1 \mathrm{~km}$ from the initial case, with no shared borders or reported close contacts with neighbouring horses.

Property E was a stock horse stud property with 16 horses, including two horses kept on the property by another owner. The property owner reported that all 16 horses eventually developed clinical symptoms of EI. Property E was approximately $1 \mathrm{~km}$ away from the nearest known 
Table 2. Equine influenza in selected study area properties, equine influenza outbreak, NSW, 2007

\begin{tabular}{lrrc} 
Property & \multicolumn{2}{c}{ Horses } & Onset date \\
& $n$ & $\%$ sick & \\
\hline A & 75 & 100 & $04 / 09 / 2007$ \\
B & 11 & 100 & $06 / 09 / 2007$ \\
C & 6 & 100 & $08 / 09 / 2007$ \\
D & 67 & 67 & $09 / 09 / 2007$ \\
E & 16 & 100 & $10 / 09 / 2007$ \\
F & 8 & 75 & $20 / 09 / 2007$ \\
G & 1 & 0 & - \\
H & 0 & & - \\
I & 0 & & - \\
J & 0 & & - \\
\hline
\end{tabular}

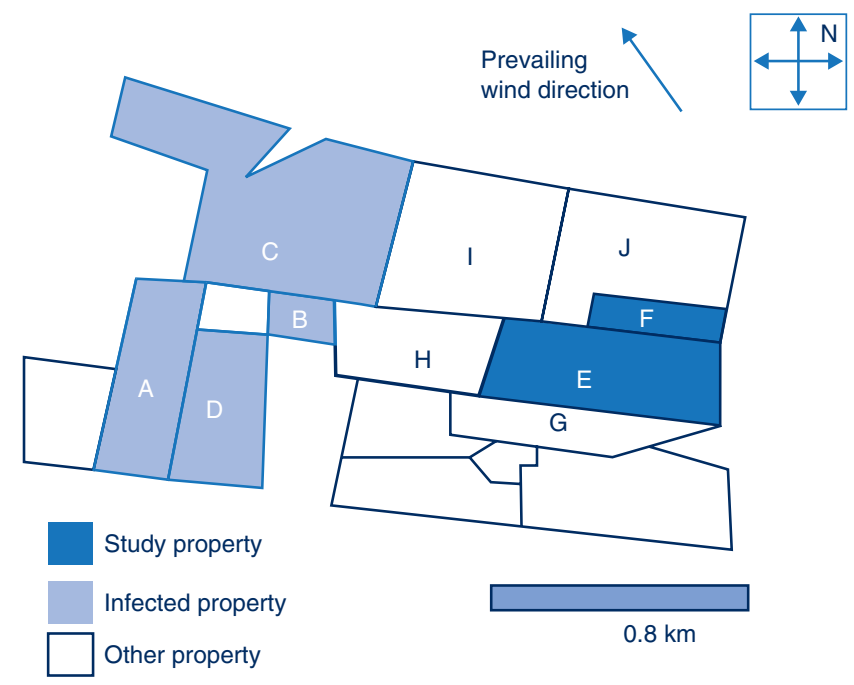

Figure 1. Selected study area properties, equine influenza outbreak, NSW, 2007. Source: NSW Department of Primary Industries. FrontGate Geographical Information System.

infected property. There are five properties surrounding property E. Of these, three (H, I and J) were reported by the owner of property $\mathrm{E}$ to have no resident horses (Figure 1).

The owner reported that none of the horses were moved off property $\mathrm{E}$ or shared equipment with other properties in the 10 days prior to the onset of symptoms. He reported that visitors to the property, including the owner of the two agisted horses on the property, had no contact with other horses. Other family members living on the property had minimal contact with the horses and reportedly had no contact with other horses outside property E. All horses on property $\mathrm{E}$ were fed grain pellets from a local supplier. The owner reported that there had been no deliveries to the property in the 10 days prior to the onset of symptoms. There was one dog on property E that was reported to visit property F regularly.

The owner stated that he also owned horses on another property $1-2 \mathrm{~km}$ away but reported no contact with these horses since the onset of symptoms in horses on property $\mathrm{E}$. The horses on the other property had not displayed any clinical symptoms.

The owner noted that when sick, horses coughed up undigested grain pellets, coughing sputum over the feed. A number of birds had been observed eating this feed and bathing in water troughs. Two dead birds were subsequently seen in the horse yards but were discarded and therefore not available for testing.

Property F first reported symptoms on 20 September (10 days after the onset of illness on property E). The owner reported that six of the eight horses on the property developed clinical symptoms of EI. Property F shared a border with property E, which was likely to have been the source of infection because of its close proximity.

Property G shared a border with property E and had one 30-year-old horse. The horse had not been broken in, no equipment was used (and therefore shared), and the horse had never left the property. The owner onsite had checked the horse daily for clinical symptoms and it was asymptomatic at the time of interview.

Property I reported horses had been kept on the property approximately 12 months before. The owners of properties $\mathrm{H}$ and $\mathrm{J}$ reported no horses as currently resident onsite.

Daily observations from a weather station approximately $6 \mathrm{~km}$ north-east of the study group were used as a proxy measure for the area of interest. Weather conditions during the incubation period for the initial case on property $\mathrm{E}$ (estimated from 4 to 10 September) were obtained from the Bureau of Meteorology. ${ }^{12}$ The weather station reported rain and easterly and south-easterly winds during this period.

\section{Discussion}

This study of geographically separate properties infected with EI with no apparent epidemiological links found that transmission had occurred with a separation of approximately $1 \mathrm{~km}$ between known infected properties. Infection still occurred despite the owner on property E reporting implementation of biosecurity measures such as disinfection of equipment and personnel, minimising visitors and their contact with horses and moving horses away from boundary lines.

The owner of property E did not report possible transmission by nose-to-nose contact with infected horses, shared 
equipment, or visitors to the property with other horse contacts. However, it is difficult to exclude fomite transmission as the source of infection because of reliance on accurate recall and the legal requirements and penalties that could result from disclosing such information.

Interviews with property owners in the study identified the possibility of mechanical transfer of infection by birds or other animals in the spread of EI. Five property owners (A, B, D, E and H) reported an increased number of birds around properties in recent months that were observed eating horse grain and bathing in water troughs. Birds that ate food in and around feed bins may have been exposed to respiratory secretions from infected horses to become a source of mechanical virus transfer. These birds were not available for testing. The owner of property E hypothesised that the birds travelled between stables looking for food, particularly during the current drought when the usual food supplies were limited.

Studies into foot-and-mouth disease transmission have reported that birds may act as potential fomites for mechanical transfer as respiratory secretions - and consequently virus - adhere to feathers. ${ }^{13}$ The foot-and-mouth disease virus is reportedly able to survive for short periods on the body of animals, including for up to 91 hours on the feathers of live birds. ${ }^{14}$ The EI virus has been reported to survive in water and soil for varying time periods dependent on temperature and $\mathrm{pH} ;{ }^{1}$ however we were unable to find data on the survival of the virus on feathers or other animals.

While birds are one potential mode of mechanical transfer of EI, it is possible that dogs or other mammals may also facilitate the spread of the EI virus for a short time and distance in the vicinity of an EI outbreak.

The weather conditions reported during the incubation period for property E (rain and south-easterly winds) indicate that windborne transmission of EI from property A would be unlikely. Research into windborne spread of footand-mouth disease found that transmission was reliant on high humidity, low wind speeds, and the absence of heavy rain. ${ }^{15}$ Further experimental trials would be necessary to test the feasibility of windborne virus transmission for EI.

There were time delays of approximately 3 weeks between the notification of infection and the interview. This may have resulted in inaccurate recall of information by the property owners. In addition, owners would have been aware of legal requirements of reporting and compliance with biosecurity practices. Owners interviewed in the study were unable to be guaranteed confidentiality, and may have been less likely to report breaches in practice during their interview. Owners of infected properties in only one cluster were interviewed and so these findings may not be generalised.
Because of biosecurity measures implemented on infected properties and the risk of infection to reportedly noninfected properties, interviews were limited to either a telephone call or were conducted at property boundaries. Consequently, interviewers were not able to carry out a physical investigation of the properties. The study was, however, able to use the FrontGate Geographic Information System to ascertain property borders.

\section{Conclusion}

The hypothesis-generating questionnaires did not identify epidemiological links between these infected properties but described the potential for mechanical spread via birds or other animals. Further research, including laboratory testing of bird plumage following contact with infected horses, may be useful to confirm the possibility of avian fomite transmission. Additional study of clusters in other areas may be useful to better understand the epidemiological features of EI.

\section{Acknowledgments}

We would like to thank the equine influenza emergency management team from the NSW Department of Primary Industries including Bruce Christie, Steve Dunn and the veterinary epidemiologists for their support and advice during this study. We would also like to acknowledge the work of public health unit staff involved throughout the management of the equine influenza outbreak.

\section{References}

1. Animal Health Australia. Disease strategy: Equine influenza (Version 3.0). Australian Veterinary Emergency Plan (AUSVETPLAN), Edn 3. Canberra: Primary Industries Ministerial Council; 2007.

2. Miller WC. Equine influenza: further observations on the 'coughing' outbreak, 1965. Vet Rec 1965; 77(16): 455-6.

3. Studdert M. Equine influenza in Australia can be controlled and eradicated. Queensland Department of Primary Industries. Available from: http://www.dpi.qld.gov.au/cps/rde/xchg/dpi/ hs.xsl/27_7495_ENA_HTML.htm (Cited September 2007.)

4. Callinan I. Equine influenza: the August 2007 outbreak in Australia. Report of the Equine Influenza Inquiry. Available from: http://www.equineinfluenzainquiry.gov.au (Cited 23 July 2009.)

5. Department of Primary Industries. Equine influenza FAQs about the disease and symptoms. Available from: http://www.dpi.nsw.gov.au/agriculture/livestock/horse/ influenza/faqs/disease (Cited October 2007.)

6. Dalglish AR. The International Movement of Horses: The current infectious disease situation. Proceedings of the 9th International Conference of Racing Analysts and Veterinarians. New Orleans, USA, 1992.

7. Huntingdon PJ. Equine influenza: the disease and its control. Technical report series No. 184. Melbourne: Department of Agriculture and Rural Affairs, Victoria; 1990.

8. Guthrie AJ, Stevens KB, Bosman PP. The circumstances surrounding the outbreak and spread of equine influenza in South Africa. Rev Sci Tech 1999; 18(1): 179-85.

9. Exotic Diseases of Animals Act 1991 (NSW). No. 73, 1991. 
10. Department of Primary Industries. 18 September media release. Available from: http://www.dpi.nsw.gov.au/ aboutus/news/recent-news/agriculture-news-releases/reportsick-horses (Cited October 2007.)

11. Department of Primary Industries. FrontGate Geographical Information System.

12. Bureau of Meteorology. Available from: http://www.bom. gov.au/climate/dwo/200709/html/IDCJDW2024. 200709.shtml (Cited November 2007.)

13. Garner G, Windborne HD. Spread Case Study: Foot-andMouth Disease Presentation 2007. Department of Agriculture, Fisheries and Forestry, Canberra, ACT.
14. University of New Hampshire Cooperative Division. Foot and Mouth Disease Guidelines. Available from: http://extension.unh.edu/pubs/4HPubs/YFMGuide.pdf (Cited September 2007.)

15. Wisconsin Department of Natural Resources. Foot-and-Mouth Disease: Issues for Wisconsin Wildlife. Available from: http://www.dnr.state.wi.us/org/land/wildlife/whealth/ issues/fmd.htm (Cited October 2007.) 